\title{
Characteristics and risk factors of children with sleep-disordered breathing in Wuxi, China
}

Yun Guo ${ }^{1+}$, Zhenzhen Pan ${ }^{1 \dagger}$, Fei Gao ${ }^{2}$, Qian Wang ${ }^{1}$, Shanshan Pan ${ }^{1}$, Shiyao Xu' ${ }^{1}$ Yu Hui ${ }^{1}$, Ling Li ${ }^{1 *}$ (D) and Jun Qian ${ }^{1}$

\begin{abstract}
Background: Sleep-disordered breathing (SDB) is a common syndrome in children, related to their immune responses, cardiovascular function, and neurocognitive function. This study aimed to determine the prevalence of SDB among children in Wuxi, China, and to evaluate the protective and risk factors of SDB in children.

Methods: A cross-sectional study was conducted on children attending different schools across Wuxi, China, aged 3-14 years old. Of a total of 5630 questionnaires distributed to the parents of the children, 3997 (71.0\%) were deemed to be valid. The data on the general sociodemographic factors, children's allergy and sleep characteristics, and the parents' sleep characteristics were also collected. The Paediatric Sleep Questionnaire (PSQ) score was used to identify children at high risk of SDB. Odds ratios (ORs) and 95\% confidence intervals (Cls) were calculated by logistic regression.
\end{abstract}

Results: The prevalence of SDB in this cohort was $13.4 \%(N=534)$. SDB prevalence significantly differed in children with asthma (28.2\% vs. $12.8 \%, P<0.001)$, eczema (19.0\% vs. $10.0 \%, P<0.001)$, urticaria $(16.4 \%$ vs. $12.9 \%, P<0.01)$ and rhinitis (21.4\% vs. 10.7\%, P<0.001). No significant differences were found in SDB prevalence with respect to pillow material or quilt material. On multivariate logistic regression analysis, asthma (OR 1.986 (95\% Cl 1.312-3.007), $P<$ 0.01), eczema (OR 1.675 (95\% Cl 1.377-2.037), $P<0.001$ ), rhinitis (OR 1.998 (95\% Cl 1.635-2.441), suffered from familial sleep sickness (OR $2.416(95 \% \mathrm{Cl} 1.975-2.955), P<0.001)$ and whose mothers slept for a shorter duration (6 h-8 h: OR 1.370 (95\% Cl 1.089-1.724), $P<0.01$; $<6$ h: OR 3.385(95\% Cl 2.098-5.461), $P<0.001$ ) increased the odds of having SDB. The incidence of SDB significantly decreased with children's age (6-11 years old: OR 0.768 (95\% Cl 0.597-0.989), $P<0.05$; 12-14 years old: OR 0.691 (95\% Cl 0.530-0.901), $P<0.01$ ).

Conclusion: The results of this study demonstrated that atopic diseases (asthma, eczema, and rhinitis) and family sleep habits were risk factors for SDB in children in Wuxi, China.

Keywords: Sleep, Sleep-disordered breathing, Prevalence, Asthma, Risk factor

\footnotetext{
* Correspondence: lu-01cy@163.com

†Yun Guo and Zhenzhen Pan contributed equally to this work.

'Department of Pediatric Respiratory, Wuxi Children's Hospital, Wuxi Clinical

Medical College Affiliated to Nanjing Medical University, No.299-1 at

Qingyang Road, Liangxi District, 214023 Wuxi, Jiangsu Province, People's

Republic of China

Full list of author information is available at the end of the article
}

(c) The Author(s). 2020 Open Access This article is licensed under a Creative Commons Attribution 4.0 International License, which permits use, sharing, adaptation, distribution and reproduction in any medium or format, as long as you give appropriate credit to the original author(s) and the source, provide a link to the Creative Commons licence, and indicate if changes were made. The images or other third party material in this article are included in the article's Creative Commons licence, unless indicated otherwise in a credit line to the material. If material is not included in the article's Creative Commons licence and your intended use is not permitted by statutory regulation or exceeds the permitted use, you will need to obtain permission directly from the copyright holder. To view a copy of this licence, visit http://creativecommons.org/licenses/by/4.0/. The Creative Commons Public Domain Dedication waiver (http://creativecommons.org/publicdomain/zero/1.0/) applies to the data made available in this article, unless otherwise stated in a credit line to the data. 


\section{Background}

Sleep quality is critical for the growth and development of children [1]. Sleep-disordered breathing (SDB) is a syndrome common in childhood, the spectrum of which ranges from primary snoring to partial or complete airway obstruction, termed obstructive sleep apnea syndrome (OSAS) [2]. It is important to determine the prevalence of SDB in children because of its association with the functioning of various organs, including immune responses, cardiovascular function, and neurocognitive function [2].

The prevalence of SDB has been reported to be 5.1$13.3 \%$ in children [3-12] and $8.6-57.8 \%$ in asthmatic children $[1,6-8,11-13]$. There are, however, few studies that have explored the prevalence of SDB in China. A study in 2015 reported the proportion of children with sleep quality problems was $8.87 \%$ in Beijing [14]. In 2017, the prevalence of SDB increased to $11.6 \%$ in the same city [1]. Another multicentric cross-sectional study involving 22,478 children from eight cities in China revealed a prevalence rate of SDB at $12.0 \%$ [10]. The prevalence of SDB is found to be related to the ethnic origin of the population [15] and environment [16]. Its prevalence needs to be ascertained and undated in the different regions of the same country and other countries worldwide.

As a fast-developing country, the incidence of atopic diseases, children's differing sleep environments and parents' various sleep patterns are evolving in China. However, this may cause SDB, or rather even worsen its occurrence. Thus, the identification of risk factors for SDB is necessary to develop treatments targeted towards these factors.

Recently, a number of different tools have been developed for the diagnosis of SDB. Polysomnography is considered the gold standard method for OSA diagnosis. This technique involves the measurement of various neurophysiological and cardiorespiratory parameters. However, its high cost and limited availability in health centers limit its application in research, especially epidemiological research, which requires large sample sizes. Given these limitations, several sleep questionnaires have been developed. The Paediatric Sleep Questionnaire (PSQ), developed by Chervin et al. [17], has a low cost and a precise cut-off score $(>0.33)$, and identifies children with OSAS with a sensitivity of $83 \%$ and a specificity of $87 \%$. Li et al. confirmed that the PSQ was a successful methodology for the investigation of childhood SDB in Beijing, China, thereby supporting the applicability and generalizability of the PSQ in a large epidemiological survey of childhood SDB in China [18].

The objective of this study was to determine the prevalence of SDB among children in Wuxi, China by using PSQ. Several risk factors were analyzed: atopy diseases (asthma, eczema, urticarial and rhinitis), sleep environment (Pillow material and Quilt material), sleep habits (sleeping position and child independence), parents' sleep patterns, and familial sleep sickness. Based on these identified risk factors for SDB, the development of treatments is of great importance. This study is therefore necessary for the development of public health utility.

\section{Methods}

\section{Setting, sampling, and participants}

The present study utilized a cross-sectional, randomized, stratified, multistage cluster sampling methodology. According to the statistical formula, $\mathrm{n}=\frac{Z_{\alpha / 2}^{2} P(1-P)}{\delta^{2}}$, assuming SDB prevalence was about $10 \%$ in children $[1,10,14]$, significance at $\alpha=0.05$ with $Z_{\alpha / 2}$ of 1.96 and acceptable error at $0.1 \mathrm{p}$, the sample size was calculated as 3457 . Allowing for a $20 \%$ non-response rate, the final intended sample size was set as 4350 .

This study was conducted in Wuxi, Jiangsu, China, divided into 5 districts. Based on the school distribution in each region $(20.6,27.7,17.9,17.9$ and $15.9 \%)$, the regional sample size was determined as $896,1205,779$, 779 and 692, respectively. The respondents were recruited from 9 kindergartens, 10 primary schools, and 9 middle schools, and encompassed children aged 3-14 years. Base on the sample size of each group and school scale, the selection of the school and each grade among the same educational institutions was based on computer-generated random numbers [18].

\section{Questionnaire}

General sociodemographic data were collected, including gender, age, weight $(\mathrm{kg})$, and height $(\mathrm{cm})$. Weight and height were measured by school doctors and investigating doctors upon return of questionnaires. Body mass index (BMI) was calculated as weight $[\mathrm{kg}] /$ height $\left[\mathrm{m}^{2}\right]$. The survey included children's allergy information such as diagnosis of asthma, diagnosis of eczema, diagnosis of urticaria and diagnosis of rhinitis. In addition, data were collected on sleep characteristics, namely pillow material, quilt material, sleeping position, and sleep environment. Data on family sleep characteristics were also collected, namely parents' sleeping rules, bedtime, and daily sleep duration, as well as familial sleep sickness.

Atopic disease (asthma, eczema, urticaria, and rhinitis) diagnoses were re-confirmed by a doctor. The diagnosis of asthma was done in accordance with the guidelines for the diagnosis and optimal management of asthma in children [19]. Guidelines for diagnosis and treatment of allergic rhinitis and Clinical Practice Guidelines for diagnosis and treatment of allergic rhinitis in pediatrics were used to diagnose rhinitis $[20,21]$. Those with urticaria and eczema were diagnosed previously, and our doctor 
confirmed the diagnoses by reviewing previous electronic or paper medical records.

\section{Sleep and respiratory data}

In this study, the PSQ was completed by the parents of each child to assess sleep-associated respiratory symptoms [17]. The PSQ is a multi-page questionnaire that consists of closed question-items and several queries on pediatric sleep disorder symptoms. This questionnaire has frequently been used for research $[1,11,12,14,16$, $18,22-25]$. It comprises 22 questions on snoring, sleepiness, and behavioral problems. The three possible responses to each question were "yes," "no," and "don't know"; the questionnaire was deemed invalid if any question was answered with "don't know." The total number of "yes" answers was calculated, and was divided by the total number of answers. Children with a score of $>0.33$ were considered to be at high risk of SDB [17]. To remove the bad inference of flu or other acute infection on sleep, the questionnaire needed parents to assess children's sleep actions during the past month and sleep conditions during infection was excluded since these may not have been typical.

\section{Data inclusion and exclusion}

The questionnaire was sent to parents by the school teacher and the parents took it home to complete it. The questionnaire was collected 1 week later. After recovery, the missing values of more than $10 \%$ of the items in the PSQ were excluded, and the remaining valid questionnaires were signed by a supervisor.

\section{Data processing}

EpiData V.3.1 software (The EpiData Association, Odense, Denmark) was used for data entry. Two staff members independently entered the questionnaire data, and the quality of these data was checked by a third member of the staff. Coding and double entry of the questionnaire data were independently carried out by two professional data-entry staff.

\section{Statistical analysis}

SPSS Statistics 23.0 for Win10 (IBM, New York, U.S.) was used for data processing. Normally distributed data are expressed as mean \pm standard deviation. Differences between groups were analyzed using the $t$-test if the group variances were homogeneous or the Mann-Whiney U test if the group variances were heterogeneous. Non-normally distributed data are represented as the median and interquartile range (IQR). Pearson's chi-squared test or Fisher's exact test was used to analyze these data. The Chi-square test, $\mathrm{t}$-test, and Mann-Whiney U test were performed to select possible risk factors for SDB. Stepwise logistic regression was performed to reduce the questionnaire items to the set of items that were risk or protect factors in SDB. A $P$ value of 0.05 was selected a priori as the criterion for item retention and finally filtered to six variables. These six variables were analyzed by multivariate logistic regression to explore the risk factors for SDB. Odds ratios (ORs) and $95 \%$ confidence intervals (CIs) were calculated by logistic regression. A $P$-value $<0.05$ was considered statistically significant.

\section{Results}

In total, 5630 questionnaires were distributed to the parents of these children and 4599 questionnaires were returned, with a response rate of $81.7 \%$, fulfilling more than the expected sample size of 4350 . Unreturned questionnaires were considered to be due to the following factors: some children live with grandparents, and their grandparents do not have the ability to complete the questionnaire; the questionnaire was taken home by the parent to complete, and some parents may have forgotten to complete or return it. There were 602 questionnaires that were excluded because of incompleteness and false information. Finally, a total of 3997 (71.0\%) were deemed to be valid. Sample characteristics difference between complete responders and incomplete responders were not significant, they were described in supplementary Table 1 .

In total, 3997 children were included in this study, $47.7 \%$ (1906) of whom were male. The mean age and BMI of the children were $9.50 \pm 3.12$ years and 16.64 (IQR 14.99-18.84) $\mathrm{kg} / \mathrm{m}^{2}$, respectively. Table 1 shows the demographic characteristics of the study population, categorized into SDB and non-SDB groups according to PSQ score. The overall prevalence of SDB was $13.4 \%$ $(N=534)$. SDB prevalence significantly differed between allergy groups: $28.2 \%$ of children with asthma had SDB (37/131, $\left.X^{2}=25.922, P<0.001\right), 19.0 \%$ of children with eczema had SDB (283/1487, $\left.\chi^{2}=65.802, \quad P<0.001\right)$, $16.4 \%$ of children with urticaria had SDB $\left(78 / 475, x^{2}=\right.$ 4.364, $P<0.05$ ), and $21.4 \%$ of children with rhinitis had SDB $\left(215 / 1003, X^{2}=75.442, \quad P<0.001\right)$. No significant differences were found between children with SDB and those without SDB with respect to pillow material or quilt material. The prevalence of SDB was significantly higher in children who slept in the prone position (18.3\%), than in those who slept in the lateral position $(12.8 \%)$ or supine position $(13.0 \%)\left(\chi^{2}=8.007, P<0.05\right)$. Children who share a bed with their parents while sleeping tended to show a higher prevalence of SDB compared to those who slept alone $(15.1 \%$ versus 12.7 and $12.4 \%)$, although the differences between these groups were not significant $\left(\chi^{2}=5.651, P>0.05\right)$.

A child's risk of SDB was found to be associated with the sleep conditions, characteristics, patterns and habits of their family (Table 2). A significantly 
Table 1 Sample characteristics

\begin{tabular}{|c|c|c|c|c|c|}
\hline Characteristic & $\begin{array}{l}\text { Total } \\
(n=3997)\end{array}$ & $\begin{array}{l}\text { SDB } \\
(n=534,13.4 \%)\end{array}$ & $\begin{array}{l}\text { NO SDB } \\
(n=3463,86.6 \%)\end{array}$ & Group differences & $P$ \\
\hline Age in years (mean SD) & $9.50 \pm 3.12$ & $9.00 \pm 3.17$ & $9.58 \pm 3.11$ & $t=-3.974$ & $0.000^{*}$ \\
\hline Male(\%) & $1906(47.7)$ & $271(14.2)$ & 1645 (85.8) & $x^{2}=2.318$ & NS \\
\hline $\begin{array}{l}\text { Height (cm) } \\
\text { median (min-max) }\end{array}$ & 139.00 (120.00-152.00) & $135.00(104.00-150.00)$ & 140.00 (120.00-153.00) & $Z=-3.498$ & $0.000^{*}$ \\
\hline $\begin{array}{l}\text { Weight (kg) } \\
\text { median (min-max) }\end{array}$ & $31.00(22.00-42.50)$ & $30.00(21.00-43.00)$ & $32.00(22.50-43.00)$ & $Z=-2.879$ & 0.004 \\
\hline $\begin{array}{l}\text { BMI } \\
\text { median (min-max) }\end{array}$ & 16.64 (14.99-18.84) & $16.43(14.88-19.00)$ & 16.65 (15.00-18.85) & $Z=-0.787$ & NS \\
\hline Asthma & 131 & $37(28.2)$ & $94(71.8)$ & $x^{2}=25.922$ & $0.000^{*}$ \\
\hline Eczema & 1487 & $283(19.0)$ & $1204(81.0)$ & $x^{2}=65.802$ & $0.000^{*}$ \\
\hline Urticaria & 475 & $78(16.4)$ & $397(83.6)$ & $x^{2}=4.364$ & $0.044 \dagger$ \\
\hline Rhinitis & 1003 & $215(21.4)$ & 788 (78.6) & $x^{2}=75.442$ & $0.000^{*}$ \\
\hline Sleep duration/night, hours median (min-max) & $9.00(8.08-9.50)$ & $9.00(8.00-9.50)$ & $9.00(8.10-9.50)$ & Z-0.829 & NS \\
\hline $\begin{array}{l}\text { Day naps, hours } \\
\text { median (min-max) }\end{array}$ & $0.00(0.00-1.00)$ & $0.00(0.00-1.50)$ & $0.00(0.00-1.00)$ & $Z=-0.787$ & 0.022 \\
\hline Pillow material & 3864 & $520(13.5)$ & $3344(86.5)$ & $x^{2}=8.908$ & NS \\
\hline Buckwheat & 765 (19.8) & $95(12.4)$ & $670(87.6)$ & & \\
\hline Silk & $153(4.0)$ & $28(18.3)$ & $125(81.7)$ & & \\
\hline Down/ Feather & $337(8.7)$ & $40(11.9)$ & $297(88.1)$ & & \\
\hline Sponge & $812(21.0)$ & $118(14.5)$ & $694(85.5)$ & & \\
\hline Chemical fiber & $616(15.9)$ & $69(11.2)$ & $547(88.8)$ & & \\
\hline Others & $1181(30.6)$ & $170(14.4)$ & $1011(85.6)$ & & \\
\hline Quilt material & 3877 & $521(13.4)$ & $3356(86.6)$ & $x^{2}=9.745$ & NS \\
\hline Cotton & $2497(64.4)$ & $324(13.0)$ & $2173(87.0)$ & & \\
\hline Down/ Feather & $246(6.3)$ & $43(17.5)$ & $203(82.5)$ & & \\
\hline Silk & $851(21.9)$ & $121(14.2)$ & $730(85.8)$ & & \\
\hline Wool & $78(2.0)$ & $6(7.7)$ & $72(92.3)$ & & \\
\hline Blanket & $29(0.7)$ & $2(6.9)$ & $27(93.1)$ & & \\
\hline Chemical fiber & $112(2.9)$ & $19(17.0)$ & $93(83.0)$ & & \\
\hline Others & $64(1.7)$ & $6(9.4)$ & $58(90.6)$ & & \\
\hline Sleeping position & 3997 & $534(13.4)$ & 3463 & $x^{2}=8.007$ & $0.018+$ \\
\hline Supine & 1275 (31.9) & $166(13.0)$ & 1109 (87.0) & & \\
\hline Lateral & $2378(59.5)$ & $305(12.8)$ & $2073(81.2)$ & & \\
\hline Prone & $344(8.6)$ & $63(18.3)$ & $281(81.7)$ & & \\
\hline Sleep environment & 3997 & $534(13.4)$ & 3463 & $x^{2}=5.396$ & NS \\
\hline Shares a bed & $1307(32.7)$ & $198(15.1)$ & 1109 (84.9) & & \\
\hline Shares a bedroom & $631(15.8)$ & $80(12.7)$ & $551(87.3)$ & & \\
\hline Sleep alone & 2059 (51.5) & $256(12.4)$ & $1803(87.6)$ & & \\
\hline
\end{tabular}

Data were presented as mean $\pm \mathrm{SD}$, median, min-max or $\mathrm{n}(\%)$ unless otherwise stated. $\mathrm{P}<0.05$ was considered statistically significant difference. NS, no significant difference; SDB, sleep disorder breathing; SD, standard deviation; min-max, minimum and maximum interquartile range

higher proportion of children whose fathers and mothers both exhibited irregular sleeping patterns suffered from SDB compared to those whose fathers and mothers both exhibited regular sleeping patterns $\quad(X 2=50.994, \quad P<0.001 ; \quad X 2=52.101, \quad P<$ 0.001 , respectively). The prevalence of SDB was significantly higher in children whose parents went to sleep later and had a shorter duration of sleep $(P<0.05)$. The prevalence of SDB was significantly higher in children from families with a history of familial sleep sicknesses than in those from normal families $\left(X^{2}=99.219, P<0.001\right)$. 
Table 2 Family sleep characteristics

\begin{tabular}{|c|c|c|c|c|c|}
\hline Characteristic & $\begin{array}{l}\text { Sample } \\
(\mathrm{n}=3997)\end{array}$ & $\begin{array}{l}\text { SDB } \\
(n=534)\end{array}$ & $\begin{array}{l}\text { NO SDB } \\
(n=3463)\end{array}$ & Group differences & $P$ values \\
\hline Father's sleep patterns & 3997 & $534(13.4)^{*}$ & 3463 & $x^{2}=50.994$ & $0.000^{*}$ \\
\hline Irregular & 817 & $163(20)$ & 654 & & \\
\hline Regular & 2486 & $318(12.8)$ & 2168 & & \\
\hline Very regular & 694 & $53(7.6)$ & 641 & & \\
\hline Mother's sleep patterns & 3997 & $534(13.4)^{*}$ & 3463 & $x^{2}=52.101$ & $0.000^{*}$ \\
\hline Irregular & 385 & $90(23.4)$ & 295 & & \\
\hline Regular & 2833 & $381(13.4)$ & 2452 & & \\
\hline Very regular & 779 & $63(8.1)$ & 716 & & \\
\hline Father's bedtime & 3997 & $534(13.4)^{*}$ & 3463 & $x^{2}=30.033$ & $0.000^{*}$ \\
\hline $21-22$ & 1247 & $118(9.5)$ & 1129 & & \\
\hline $22-24$ & 2440 & $355(14.5)$ & 2085 & & \\
\hline After 24 & 310 & $61(19.7)$ & 249 & & \\
\hline Mother's bedtime & 3997 & $534(13.4)^{*}$ & 3604 & $x^{2}=26.946$ & $0.000^{*}$ \\
\hline $21-22$ & 2316 & $265(11.4)$ & 2051 & & \\
\hline $22-24$ & 1572 & $241(15.3)$ & 1331 & & \\
\hline After 24 & 109 & $28(25.7)$ & 81 & & \\
\hline Father's sleep duration & 3997 & $534(13.4)^{*}$ & 3463 & $x^{2}=14.940$ & $0.001^{*}$ \\
\hline$>8 \mathrm{~h}$ & 686 & $68(9.9)$ & 618 & & \\
\hline $6 \mathrm{~h}-8 \mathrm{~h}$ & 3093 & $423(13.7)$ & 2670 & & \\
\hline$<6 \mathrm{~h}$ & 218 & $43(19.7)$ & 175 & & \\
\hline Mother's sleep duration & 3997 & $534(13.4)^{*}$ & 3463 & $x^{2}=27.318$ & $0.000^{*}$ \\
\hline$>8 \mathrm{~h}$ & 1091 & $113(10.4)$ & 978 & & \\
\hline $6 \mathrm{~h}-8 \mathrm{~h}$ & 2790 & $390(14.0)$ & 2400 & & \\
\hline$<6 h$ & 116 & $31(26.7)$ & 85 & & \\
\hline Familial sleep sickness & $637(20.9)$ & $199(23.8)^{*}$ & 638 & $x^{2}=99.219$ & $0.000^{*}$ \\
\hline
\end{tabular}

Data were presented as $\mathrm{n}(\%)$ unless otherwise stated. $P<0.05$ was considered statistically significant difference. SDB sleep disorder breathing

The Chi-square test, $\mathrm{t}$-test and Mann-Whiney $\mathrm{U}$ test were performed to select possible risk factors for SDB. According to pervious results, 13 items were possible risk factors for SDB. On univariate logistic regression analysis, SDB incidence decreased with age (6-11 years old: OR 0.788 (95\% CI 0.619-1.002), $P>0.05 ; 12-14$ years old: OR $0.658(95 \%$ CI $0.513-0.844), P<0.01)$. Atopic diseases including asthma (OR 2.668 (95\% CI 1.803-3.948), $P<0.001$ ), eczema (OR 2.115 (95\% CI $1.760-2.542), \mathrm{P}<0.001$ ), urticaria (OR 1.321 (95\% CI 1.017-1.717), $\mathrm{P}<0.001$ ) and rhinitis (OR 2.288 (95\% CI 1.891-2.768) increased the odds of having SDB. Sleep patterns (irregular) and habits (sleep less than $8 \mathrm{~h}$ or sleeps late) of their parents were predictors of SDB. Familial sleep sickness was also a risk factor for SDB (OR 2.630 (95\% CI 2.164-3.198), $P<0.001$ ) (Supplementary Table 2).

The variables including age, asthma status, eczema status, rhinitis status, mother's sleep duration status and familial sleep sickness status were finally included in the multiple logistic regression analysis $(P<0.05)$. SDB incidence significantly decreased with age $(6-11$ years old: OR 0.768 (95\% CI $0.597-0.989$ ), $\mathrm{P}<0.05 ; 12-14$ years old: OR 0.691 (95\% CI 0.530-0.901), $P<0.01$ ). A number of atopic diseases were predictors of SDB, namely asthma (OR 1.986 (95\% CI 1.312-3.007), $P<0.01$ ), eczema (OR 1.675 (95\% CI 1.377-2.037), $P<0.001$ ) and rhinitis (OR 1.998 (95\% CI 1.635-2.441). Children who suffered from familial sleep sicknesses (OR 2.416 (95\% CI 1.975-2.955), $\mathrm{P}<0.001)$ and whose mothers slept for a shorter duration (6 h-8 h: OR 1.370 (95\% CI 1.089-1.724), P < 0.01; <6 h: OR 3.385(95\% CI 2.098-5.461), $\mathrm{P}<0.001)$ also increased the odds of having SDB (Table 3).

\section{Discussion}

China is a rapidly industrializing developing country with increasing attention on childhood sleep health. Although there were data of SDB being an epidemic in Beijing, China, childhood sleep habits and SDB-related symptoms of different cities may be affected by regions 
Table 3 Risk Factors for Sleep-disordered Breathing in children

\begin{tabular}{|c|c|c|c|c|}
\hline \multirow[t]{2}{*}{ Characteristic } & \multicolumn{2}{|l|}{ Univariate analysis } & \multicolumn{2}{|l|}{ Multivariate analysis } \\
\hline & $\overline{\mathrm{OR}(95 \% \mathrm{Cl})}$ & $P$ values & $\overline{\mathrm{OR}(95 \% \mathrm{Cl})}$ & $P$ values \\
\hline Age in years & & $0.004^{*}$ & & $0.022+$ \\
\hline $3-5$ & 1 & & 1 & \\
\hline $6-11$ & $0.788(0.619-1.002)$ & 0.052 & $0.768(0.597-0.989)$ & $0.041+$ \\
\hline $12-14$ & $0.658(0.513-0.844)$ & $0.001^{*}$ & $0.691(0.530-0.901)$ & $0.006^{*}$ \\
\hline Asthma & & $0.000^{*}$ & & $0.001^{*}$ \\
\hline No & 1 & & 1 & \\
\hline Yes & $2.668(1.803-3.948)$ & & $1.918(1.267-2.905)$ & \\
\hline Eczema & & $0.000^{*}$ & & $0.002^{*}$ \\
\hline No & 1 & & 1 & \\
\hline Yes & $2.115(1.760-2.542)$ & & $1.735(1.422-2.117)$ & \\
\hline Rhinitis & & $0.000^{*}$ & & $0.000^{*}$ \\
\hline No & 1 & & 1 & \\
\hline Yes & $2.288(1.891-2.768)$ & & 2.039 (1.662-2.503) & \\
\hline Mother's sleep duration & & $0.000^{*}$ & & $0.000^{*}$ \\
\hline$>8 \mathrm{~h}$ & 1 & & 1 & \\
\hline $6 \mathrm{~h}-8 \mathrm{~h}$ & $1.406(1.126-1.756)$ & $0.003^{*}$ & $1.369(1.083-1.729)$ & $0.009^{*}$ \\
\hline$<6 \mathrm{~h}$ & $3.156(2.003-4.975)$ & $0.000^{*}$ & $3.424(2.102-5.577)$ & $0.000^{*}$ \\
\hline Familial sleep sickness & & $0.000^{*}$ & & $0.000^{*}$ \\
\hline No & 1 & & 1 & \\
\hline Yes & $2.630(2.164-3.198)$ & & $2.339(1.903-2.874)$ & \\
\hline
\end{tabular}

The data from multivariate analysis were after adjusting for age, asthma status, eczema status, rhinitis status, mother's sleep duration status and familial sleep sickness status. $P<0.05$ was considered statistically significant difference. $\mathrm{Cl}$, confidence interval; OR, Odds ratios

and a survey of other cities is needed. Clear and complete epidemic statistics resulted in a growing number of people learning the importance of SDB, thereby decreasing its debilitating and costly effects in the future.

The main findings of the present study were that SDB prevalence in children aged 3-14years in Wuxi, China was $13.4 \%$. while children with asthma, eczema, urticarial or rhinitis showed an increased prevalence of SDB as compared to unaffected children. Family sleep habits (shorter maternal sleep duration, familial sleep sickness, and irregular parental sleep patterns) also resulted in a high prevalence of SDB. On multivariate logistic regression analysis, we found asthma, eczema, rhinitis, familial sleep sickness and having mothers who slept for a shorter duration increased the odds of having SDB. However, SDB incidence significantly decreased with age.

This was a cross-sectional study with a total of 3997 children aged 3-14 years. The overall SDB prevalence in this study was $13.4 \%$. In a cohort of primary school students in Japan, the prevalence of SDB varied from 8.5 to $11.3 \%$ [26]. Furthermore, in a study of a random sample of 20,152 children from eight Chinese cities, the prevalence of childhood habitual snoring was $12.0 \%$ [4]. A cross-sectional telephone questionnaire survey in which
30476 to 12 -year-old children, with no apparent health problems, reported a habitual snoring prevalence of $10.9 \%$ [27]. The prevalence of SDB in this study being higher than that reported in previous studies may be related to the population subsets, broad age range and distinctive environments.

We noticed that SDB incidence significantly decreased with age and therefore, age was a protect factor for SDB. SDB was manifested in $16.6 \%$ of children aged $3-5$ years, $13.6 \%$ of children aged $6-11$ years and $11.6 \%$ of children aged 12-14 years. The relationship between age and SDB was according to diseases, allergen exposure, studyinduced stress, sleep environment and so on. Children aged 3-5 years are susceptible to suffering from respiratory infection, and repeated infection may influence the SDB prevalence. However, the incidence of tonsillar and adenoidal hypertrophy may also lead to the peak prevalence at this age group [28]. Moreover, diagnosing asthma in children aged $3-5$ years is difficult, resulting to untreated asthma which will affect children's sleep [12]. For children aged 6-11 years, the number of respiratory infections is reduced and their SDB always associated with allergic diseases [12, 29, 30]. For children aged 12-14 years, mainly enrolled in middle schools, given heavy academic pressure and graduating pressure, 
in addition to a heavy study load and homework makes them suffer from sleep loss [31]. However, children aged 12-14 years old always sleep alone and parents cannot observe their sleep conditions very well which may affect SDB prevalence.

Among other demographic correlates, we did not identify an association between SDB symptoms and gender, correlating with the findings of a previous study [2]. An association between SDB symptoms and BMI was also not identified in this study. This is in contrast to the findings of some previous studies in children, in which obesity was identified as an important risk factor for SDB [32-34]. Obesity likely contributes to SDB by increasing fat deposition in the subcutaneous fat of the neck and other soft tissue structures, and reducing lung volume [35]; we did not, however, get a positive result possibly because the proportion of obese people in the group is low (data not shown).

The relationship between atopic diseases and SDB has gained attention in recent years. In this study, SDB prevalence significantly increased in asthmatic children than non-asthmatic children $(28.2 \%$ vs. $12.8 \%)$ and asthma was identified as a strong factor for SDB. We found children with asthma more often suffer from "heavy or loud breathing", "trouble breathing or struggle to breathe", "stop breathing during the night", "wake up feeling unrefreshed in the morning" and "wake up with headaches in the morning" than normal children (data not shown). Several studies provide evidences that SDB prevalence is highly associated with asthma. A systematic review of 17 studies involving 45,155 children found that SDB was significantly more prevalent in children with asthma than non-asthmatics (23.9\% vs. $16.7 \%)$ [5]. Asthma may impair sleep via several mechanisms. Asthma may affect sleep by changing the circadian rhythm [36, 37]. A common inflammatory pathway of the airway may also link asthma and SDB [5]. Increased inflammation and airway resistance affects the airways and causes decreased airway flow rates during sleep. Increased bronchial hyper-reactivity during sleep may be related to allergen exposure, airway cooling, hormonal changes, and parasympathetic tone $[38,39]$. These mechanisms provide evidences that poor asthma control and concomitant presence of rhinitis are associated with high risk for SDB in children [12]. In this study, about $18.3 \%(24 / 131)$ of asthmatics were not well controlled, and about $57.3 \%(75 / 131)$ of asthmatics had a concomitant presence of rhinitis.

We also found a high frequency of SDB with rhinitis (21.4\% vs. $10.7 \%)$ and rhinitis was one of the risk factors for OSA. Sleep disorder symptoms in rhinitis were different from those present in the asthmatics. Children with rhinitis more often suffer from "snoring", "heavy or loud breathing", "breathing through the mouth" and "have a dry mouth on waking up in the morning" than do normal children (data not shown), these different symptoms that indicate the mechanism through which rhinitis affect sleep were distinct. Nasal congestion caused by inflammation of the nasal mucosa may induce oral breathing, sleep disruption, and increased fatigue [40]. High presence pf adenoid hypertrophy in children with rhinitis may also result in sleep problems [41, 42]. Hence, nasal congestion and adenoidal hypertrophy are treatable causes of SDB in children [9]. A 6-week treatment with intranasal budesonide effectively reduced the severity of mild OSAS and the magnitude of the underlying adenoidal hypertrophy, and this effect persisted for at least 8 weeks after cessation of therapy [43]. Our study did not show the relationship between nasal steroids and SDB prevalence due to the missing values of more than $30 \%$. Within the present values, the usage of nasal steroids for rhinitis was low, and this may increase positive findings of SDB.

SDB prevalence significantly increased in eczema (19.0\%) and urticaria (16.4\%) in our study. Between eczema and urticaria, eczema was a higher risk factor for SDB. Skin allergic-related nocturnal itching and the subsequent scratch response are thought to induce poor sleep initiation and frequent and prolonged awakenings throughout the night [44]. A limitation of this study was the unknown proportion of children who had rashes or urticaria at time of this questionnaire which may affect SDB prevalence.

This study also assessed the relationship between sleep environment and SDB prevalence. However, we did not identify an association between pillow or quilt material and SDB prevalence. As for bed-sharing, we found children who shared a bed with their parents tended to show a higher prevalence of SDB as compared to those who shared a bedroom with their parents but slept on a separate bed or slept alone $(15.1,12.7$ and $12.4 \%$, respectively). Bed-sharing has been associated with several sleep problems in children, including frequent waking up throughout and/or an increased length of time spent awake at night, experiencing nightmares, and a shorter night-time sleep duration $[45,46]$. In a previous study, sleep problems were more common in children who shared a bed or bedroom with their parents in China [47]. Our data also showed that SDB prevalence in children who shared beds with their parents was higher, however, these differences were not significant.

In this study, the prevalence of SDB was higher in children who slept in the prone position (18.3\%) than in those who slept in the lateral position (12.8\%) or supine position $(13.0 \%)$. Children found it easier to sleep in the prone position than adults; the prone and supine positions exhibit numerous differences in the control of the cardiovascular, respiratory, and thermoregulatory systems [48]. The prone 
sleeping position has been associated with an increased risk of infant death [49]; however, the relationship between this sleeping position and SDB prevalence remains unclear.

We noticed that SDB prevalence was also associated with family sleep conditions. In addition, familial sleep sickness was identified as a risk factor for SDB (OR = 2.202). Family history has long been identified as a strong risk factor for OSAS in individuals of various ethnicities $[35,50,51]$, our data supports and extends these observations.

In addition, we evaluated whether a child's risk of SDB was affected by their parents' sleep patterns. It was shown that SDB was more prevalent in children whose parents exhibited irregular sleep patterns than in those whose parents exhibited regular sleep patterns. Furthermore, SDB was more prevalent in children whose parents went to sleep later and had a shorter sleep duration. In cases where a child's parents go to bed at a later time, their bedtime may also be delayed, resulting in shorter nocturnal sleep duration, greater nocturnal variability, and ultimately nocturnal sleep problems $[52,53]$. Although mother's sleep duration was identified as a risk factor for SDB, it is considered that parents who sleep late may notice their children's sleep conditions easily, which could have a false higher proportion of SDB. The relationship between SDB and parents' sleep patterns needs further verification.

This study has some limitations that should be noted. First, given the cross-sectional nature of this study, we were unable to establish a cause and effect relationship. In this study, SDB diagnosis was based on a parentallycompleted questionnaire. Thus, whether a child snored or stopped breathing during the night was subjective, therefore, the prevalence of SDB in this cohort may have been over or under-estimated, which may have affected the reported SDB prevalence. For disease-related studies, the usage of nasal steroids for rhinitis and the proportion of children who had rashes or urticaria at time of this questionnaire were unknown, which may affect SDB prevalence.

\section{Conclusion}

In summary, the prevalence of SDB in children in Wuxi, China was 13.4\%. Atopic diseases (asthma, eczema, and rhinitis), shorter maternal sleep duration, and familial sleep sickness were found to be risk factors for SDB, whereas increased age and regular parental sleep patterns were protective factors. Clinicians should investigate the atopic diseases related to SDB and advise parents to sleep earlier and engage in more regular treatments and counselling.

\section{Supplementary information}

Supplementary information accompanies this paper at https://doi.org/10. 1186/s12887-020-02207-5.

Additional file 1: Supplementary Table 1. Sample characteristics. Supplementary Table 2. Risk Factors for Sleep-disordered Breathing in children.

\section{Abbreviations}

SDB: Sleep-Disordered Breathing; ORs: Odds Ratios; Cls: Confidence Intervals; OSAS: Obstructive Sleep Apnoea Syndrome; PSQ: Paediatric Sleep

Questionnaire; BMI: Body Mass Index; IQR: Interquartile range

\section{Acknowledgements}

The authors would like to acknowledge teachers from different schools for their help with the initial of the project. They also acknowledge the staff of Education Bureau who have kindly provided information about the distribution and number of schools.

\section{Authors' contributions}

$\mathrm{LL}$ and JQ designed and led the research. YG and ZZP drafted the work and led the writing of the paper. YG and FG analysed and interpreted the participants data. QW, SSP, SYX and YH acquisition the data. ALL authors contributed to the implementation of the study. ALL authors read and approved the final manuscript.

\section{Funding}

This study was funded by the Medical Innovation Team of Jiangsu Province (grant number CXTDB 2017016). The Youth project of Wuxi Health and Family Planning Commission (grant number Q201837). The general Program of Nanjing Medical University (grant number 2017NJMUZD119), this fund contributed materials. Project of Wuxi Municipal Science and Technology Bureau (CSE31N1608). Wuxi health project (grant number Z201606). Wuxi Municipal Bureau on Science and Technology (grant number NZ2019026). The funding had support data collection, analysis, interpretation of the data, materials, labor service free, the publication charges for this article. The funding did not include analysis tools.

\section{Availability of data and materials}

The datasets generated and/or analysed during the current study are not publicly available due data do not have consent from all patients to share their information online but are available from the corresponding author on reasonable request.

\section{Ethics approval and consent to participate}

Ethical approval was provided by the medical ethics committee of Wuxi Children's Hospital (No. WXCH2016-11-002). Informed consent was obtained from all individual participants included in the study and participant under 16 years had a written informed consent obtained from a parent.

Consent for publication

Not Applicable.

\section{Competing interests}

Author Ling Li, Jun Qian, Yun Guo and Zhenzhen Pan had received research grants from government. The authors have no conflicts of interest to declare.

\section{Author details}

${ }^{1}$ Department of Pediatric Respiratory, Wuxi Children's Hospital, Wuxi Clinical Medical College Affiliated to Nanjing Medical University, No.299-1 at Qingyang Road, Liangxi District, 214023 Wuxi, Jiangsu Province, People's Republic of China. ${ }^{2}$ Department of Intensive Care Unit, Wuxi People's Hospital, Wuxi Clinical Medical College Affiliated to Nanjing Medical University, No.299 at Qingyang Road, Liangxi District, 214023 Wuxi, Jiangsu Province, People's Republic of China. 
Received: 10 January 2020 Accepted: 16 June 2020

Published online: 26 June 2020

\section{References}

1. Li XD, Tai J, Xu ZF, Wang GX, Wu YX, Du JN, Zhang J, Peng XX, Ni X. Sleep duration and factors related to sleep loss in 3-14-year-old children in Beijing: a cross-sectional survey. Chin Med J. 2018;131(15):1799-807.

2. Zandieh SO, Cespedes A, Ciarleglio A, Bourgeois W, Rapoport DM, Bruzzese JM. Asthma and subjective sleep disordered breathing in a large cohort of urban adolescents. J Asthma. 2017;54(1):62-8.

3. Chng SY, Goh DY, Wang XS, Tan TN, Ong NB. Snoring and atopic disease: a strong association. Pediatr Pulmonol. 2004;38(3):210-6.

4. Li S, Jin X, Yan C, Wu S, Jiang F, Shen X. Habitual snoring in school-aged children: environmental and biological predictors. Respir Res. 2010;11:144.

5. Brockmann PE, Bertrand P, Castro-Rodriguez JA. Influence of asthma on sleep disordered breathing in children: a systematic review. Sleep Med Rev. 2014;18(5):393-7.

6. Corbo GM, Forastiere F, Agabiti N, Pistelli R, Dell'Orco V, Perucci CA, Valente S. Snoring in 9- to 15-year-old children: risk factors and clinical relevance. Pediatrics. 2001;108(5):1149-54.

7. Valery PC, Masters IB, Chang AB. Snoring and its association with asthma in indigenous children living in the Torres Strait and northern peninsula area. Paediatr Child Health. 2004;40(8):461-5.

8. Sulit LG, Storfer-Isser A, Rosen CL, Kirchner HL, Redline S. Associations of obesity, sleep-disordered breathing, and wheezing in children. Am J Respir Crit Care Med. 2005;171(6):659-64.

9. Ross KR, Storfer-Isser A, Hart MA, Kibler AM, Rueschman M, Rosen CL, Kercsmar CM, Redline S. Sleep-disordered breathing is associated with asthma severity in children. J Pediatr. 2012;160(5):736-42.

10. Li L, Xu Z, Jin X, Yan C, Jiang F, Tong S, Shen X, Li S. Sleep-disordered breathing and asthma: evidence from a large multicentric epidemiological study in China. Respir Res. 2015;16:56

11. Sanchez T, Rojas C, Casals M, Bennett JT, Galvez C, Betancur C, Mesa JT, Brockmann PE. Prevalence and risk factors for sleep-disordered breathing in chilean schoolchildren. Rev Chil Pediatr. 2018;89(6):718-25.

12. Perikleous E, Steiropoulos P, Nena E, lordanidou M, Tzouvelekis A, Chatzimichael A, Paraskakis E. Association of Asthma and Allergic Rhinitis with Sleep-Disordered Breathing in childhood. Front Pediatr. 2018;6:250.

13. Furtado PR, Maciel ACC, Barbosa RRT, Silva A, Freitas DA, Mendonca K Association between quality of life, severity of asthma, sleep disorders and exercise capacity in children with asthma: a cross-sectional study. Braz J Phys Ther. 2019;23(1):12-8.

14. Li HB, Tai J, Feng GS, Li XD, Du JN, Wang GX, Xu ZF, Ma J, Hu PJ, Yan XY, et al. Analysis of sleep quality and related factors among children in Beijing. Zhonghua Er Bi Yan Hou Tou Jing Wai Ke Za Zhi. 2019;54(6):416-20.

15. Redline S, Tishler PV, Hans MG, Tosteson TD, Strohl KP, Spry K. Racia differences in sleep-disordered breathing in African-Americans and Caucasians. Am J Respir Crit Care Med. 1997;155(1):186-92.

16. Sanchez T, Gozal D, Smith DL, Foncea C, Betancur C, Brockmann PE. Association between air pollution and sleep disordered breathing in children. Pediatr Pulmonol. 2019;54(5):544-50.

17. Chervin RD, Hedger K, Dillon JE, Pituch KJ. Pediatric sleep questionnaire (PSQ): validity and reliability of scales for sleep-disordered breathing snoring, sleepiness, and behavioral problems. Sleep Med. 2000;1(1):21-32.

18. Li X, Tai J, Xu Z, Ma J, Peng X, Pan Y, Yan X, Wang G, Wu Y, Zheng L, et al. Systematic investigation of childhood sleep-disordered breathing (SDB) in Beijing: validation of survey methodology. BMJ Open. 2018;8(8):e021097.

19. Subspecialty Group of Respiratory Disease. Society of Pediatrics, Chinese Medical Association, editorial Board of Chinese Journal of pediatrics: Guiderline for the diagnosis and optimal management of asthma in children. Chin J Pediatr. 2016:54(3):167-81.

20. Subspecialty Group of Rhinology, Editorial Board of Chinese Journal of Otorhinolaryngology Head and Neck Surgery Subspecialty Group of Rhinology, Society of Otorhinolaryngology Head and Neck Surgery, Chinese Medical Association: Chinese Medical Association. Guidelines for diagnosis and treatment of allergic rhinitis. Chin J Otorhinolaryngol Head Neck Surg. 2016;51(1):6-24.

21. Subspecialty Group of Rhinology, Society of Pediatrics, Chinese Mediacal Doctor Association. Clinical practice guidelines for diagnosis and treatment of allergic rhinitis in pediatric. Chinese J Pract Pediatics. 2019;34(3):169-75.
22. Sheen YH, Choi SH, Jang SJ, Baek JH, Jee HM, Kim MA, Chae KY, Han MY. Poor sleep quality has an adverse effect on childhood asthma control and lung function measures. Pediatr Int. 2017;59(8):917-22.

23. Ginis T, Akcan FA, Capanoglu M, Toyran M, Ersu R, Kocabas CN, Civelek E. The frequency of sleep-disordered breathing in children with asthma and its effects on asthma control. J Asthma. 2017:54(4):403-10.

24. Khassawneh B, Tsai SC, Meltzer LJ. Polysomnographic characteristics of adolescents with asthma and low risk for sleep-disordered breathing. Sleep Breath. 2019:23(3):943-51.

25. Baidas L, Al-Jobair A, Al-Kawari H, AlShehri A, Al-Madani S, Al-Balbeesi H. Prevalence of sleep-disordered breathing and associations with orofacial symptoms among Saudi primary school children. BMC Oral Health. 2019; 19(1):43.

26. Sakamoto N, Gozal D, Smith DL, Yang L, Morimoto N, Wada H, Maruyama K, Ikeda A, Suzuki Y, Nakayama M, et al. Sleep Duration, Snoring Prevalence, Obesity, and Behavioral Problems in a Large Cohort of Primary Schoo Students in Japan. Sleep. 2017;40(3):Zsw082.

27. Ng DK, Kwok KL, Cheung JM, Leung SY, Chow PY, Wong WH, Chan CH, Ho JC. Prevalence of sleep problems in Hong Kong primary school children: a community-based telephone survey. Chest. 2005;128(3):1315-23.

28. DelRosso LM. Epidemiology and diagnosis of pediatric obstructive sleep apnea. Curr Probl Pediatr Adolesc Health Care. 2016;46(1):2-6.

29. Leger D, Bonnefoy B, Pigearias B, de La Giclais B, Chartier A. Poor sleep is highly associated with house dust mite allergic rhinitis in adults and children. Allergy Asthma Clin Immunol. 2017;13:36.

30. Cao Y, Wu S, Zhang L, Yang Y, Cao S, Li Q. Association of allergic rhinitis with obstructive sleep apnea: a meta-analysis. Medicine (Baltimore). 2018; 97(51):e13783.

31. Sun WQ, Spruyt $K$, Chen WJ, Jiang YR, Schonfeld D, Adams R, Tseng $\mathrm{CH}_{\text {, }}$ Shen XM, Jiang $F$. The relation among sleep duration, homework burden, and sleep hygiene in chinese school-aged children. Behav Sleep Med. 2014; 12(5):398-411.

32. Redline S, Tishler PV, Schluchter M, Aylor J, Clark K, Graham G. Risk factors for sleep-disordered breathing in children. Associations with obesity, race, and respiratory problems. Am J Respir Crit Care Med. 1999;159(5 Pt 1):152732.

33. Rose S, Pretto J, Paul C, Emmett B, Hensley M, Henskens F. Relationships between nutritional knowledge, obesity, and sleep disorder severity. J Sleep Res. 2016;25(3):350-5.

34. Urrutia-Pereira M, Sole D, Chong Neto HJ, Acosta V, Cepeda AM, AlvarezCastello M, Almendarez CF, Lozano-Saenz J, Sisul-Alvariza JC, Rosario NA et al. Sleep disorders in Latin-American children with asthma and/or allergic rhinitis and normal controls. Allergol Immunopathol (Madr). 2017;45(2):14551.

35. Dudley KA, Patel SR. Disparities and genetic risk factors in obstructive sleep apnea. Sleep Med. 2016;18:96-102.

36. Zaslona Z, Case S, Early JO, Lalor SJ, McLoughlin RM, Curtis AM, O'Neill LAJ. The circadian protein BMAL1 in myeloid cells is a negative regulator of allergic asthma. Am J Physiol Lung Cell Mol Physiol. 2017;312(6):L855-60.

37. Ehlers A, Xie W, Agapov E, Brown S, Steinberg D, Tidwell R, Sajol G, Schutz $\mathrm{R}$, Weaver $\mathrm{R}$, Yu H, et al. BMAL1 links the circadian clock to viral airway pathology and asthma phenotypes. Mucosal Immunol. 2018;11(1):97-111.

38. Khan WH, Mohsenin V, D'Ambrosio CM. Sleep in asthma. Clin Chest Med. 2014;35(3):483-93.

39. Banasiak NC. Understanding the relationship between asthma and sleep in the pediatric population. J Pediatr Health Care. 2016;30(6):546-50.

40. Kimple AJ, Ishman SL. Allergy and sleep-disordered breathing. Curr Opin Otolaryngol Head Neck Surg. 2013;21(3):277-81.

41. Lou Z. Adenoid hypertrophy in children and allergic rhinitis. Eur Arch Otorhinolaryngol. 2018;275(3):831-2.

42. Dogru M, Evcimik MF, Calim OF. Does adenoid hypertrophy affect disease severity in children with allergic rhinitis? Eur Arch Otorhinolaryngol. 2017; 274(1):209-13.

43. Kheirandish-Gozal L, Gozal D. Intranasal budesonide treatment for children with mild obstructive sleep apnea syndrome. Pediatrics. 2008;122(1):e14955.

44. Camfferman D, Kennedy JD, Gold M, Simpson C, Lushington K. Sleep and neurocognitive functioning in children with eczema. Int J Psychophysiol. 2013;89(2):265-72

45. Mindell JA, Leichman ES, Walters RM. Sleep location and parent-perceived sleep outcomes in older infants. Sleep Med. 2017;39:1-7. 
46. Mileva-Seitz VR, Bakermans-Kranenburg MJ, Battaini C, Luijk MPCM. Parentchild bed-sharing: the good, the bad, and the burden of evidence. Sleep Med Rev. 2017;32:4-27.

47. Liu X, Liu L, Wang R. Bed sharing, sleep habits, and sleep problems among Chinese school-aged children. Sleep. 2003;26(7):839-44.

48. Fleming $\mathrm{P}$, Blair P, Pease A. Why or how does the prone sleep position increase the risk of unexpected and unexplained infant death? Arch Dis Child Fetal Neonatal Ed. 2017;102(6):F472-3.

49. da Silva BGC, da Silveira MF, de Oliveira PD, Domingues MR, Neumann NA Barros FC, Bertoldi AD. Prevalence and associated factors of supine sleep position in 3-month-old infants: findings from the 2015 Pelotas (Brazil) birth cohort. BMC Pediatr. 2019;19(1):165.

50. Palmer L, Buxbaum SG, Larkin EK, Patel SR, Elston RC, Tishler PV, Redline S. Whole genome scan for obstructive sleep apnea and obesity in AfricanAmerican families. Am J Respir Crit Care Med. 2004;169(12):1314-21.

51. Palmer L, Buxbaum SG, Larkin E, Patel SR, Elston RC, Tishler PV, Redline S. A whole-genome scan for obstructive sleep apnea and obesity. Am J Hum Genet. 2003;72(2):340-50

52. Zhang Z, Sousa-Sa E, Pereira J, Chaput JP, Okely A, Feng X, Santos R. Correlates of nocturnal sleep duration, nocturnal sleep variability, and nocturnal sleep problems in toddlers: results from the GET UP! Study. Sleep Med. 2019;53:124-32.

53. Quach J, Price AMH, Bittman M, Hiscock H. Sleep timing and child and parent outcomes in Australian 4-9-year-olds: a cross-sectional and longitudinal study. Sleep Med. 2016;22:39-46.

\section{Publisher's Note}

Springer Nature remains neutral with regard to jurisdictional claims in published maps and institutional affiliations.

Ready to submit your research? Choose BMC and benefit from:

- fast, convenient online submission

- thorough peer review by experienced researchers in your field

- rapid publication on acceptance

- support for research data, including large and complex data types

- gold Open Access which fosters wider collaboration and increased citations

- maximum visibility for your research: over $100 \mathrm{M}$ website views per year

At $\mathrm{BMC}$, research is always in progress.

Learn more biomedcentral.com/submissions 